\title{
Role of Radiation Therapy in Modulation of the Tumor Stroma and Microenvironment
}

\begin{abstract}
Hari Menon ${ }^{1}$, Rishab Ramapriyan ${ }^{1}$, Taylor R. Cushman ${ }^{1}$, Vivek Verma ${ }^{2}$, Hans H. Kim ${ }^{3}$, Jonathan E. Schoenhals ${ }^{4}$, Cemre Atalar ${ }^{1}$, Ugur Selek $^{5}$, Stephen G. Chun ${ }^{1}$, Joe Y. Chang ${ }^{1}$, Hampartsoum B. Barsoumian ${ }^{1}$, Quynh-Nhu Nguyen ${ }^{1}$, Mehmet Altan ${ }^{6}$, Maria A. Cortez ${ }^{7}$, Stephen M. Hahn ${ }^{1}$ and James W. Welsh ${ }^{1 *}$

${ }^{1}$ Departments of Radiation Oncology, University of Texas MD Anderson Cancer Center, Houston, TX, United States, ${ }^{2}$ Department of Radiation Oncology, Allegheny General Hospital, Pittsburgh, PA, United States, ${ }^{3}$ Department of Radiation Medicine, School of Medicine, Oregon Health and Sciences University, Portland, OR, United States, ${ }^{4}$ Medical School, University of Texas Southwestern, Dallas, TX, United States, ${ }^{5}$ Department of Radiation Oncology, School of Medicine, Koç University, Istanbul, Turkey, ${ }^{6}$ Thoracic/Head and Neck Medical Oncology, Houston, TX, United States, ${ }^{7}$ Experimental Radiation Oncology, The University of Texas MD Anderson Cancer Center, Houston, TX. United States
\end{abstract}

OPEN ACCESS

Edited by:

Patrik Andersson,

Massachusetts General Hospital, Harvard Medical School,

United States

Reviewed by:

Ainhoa Arina,

University of Chicago, United States Limin Zheng,

Sun Yat-sen University, China

*Correspondence:

James W. Welsh

jwelsh@mdanderson.org

Specialty section:

This article was submitted to

Cancer Immunity and Immunotherapy,

a section of the journal

Frontiers in Immunology

Received: 25 October 2018

Accepted: 23 January 2019

Published: 15 February 2019

Citation:

Menon $H$, Ramapriyan $R$, Cushman TR, Verma V, Kim HH,

Schoenhals JE, Atalar C, Selek U, Chun SG, Chang JY, Barsoumian HB, Nguyen Q-N, Altan M, Cortez MA Hahn SM and Welsh JW (2019) Role of Radiation Therapy in Modulation of the Tumor Stroma and Microenvironment.

Front. Immunol. 10:193.

doi: 10.3389/fimmu.2019.00193
In recent decades, there has been substantial growth in our understanding of the immune system and its role in tumor growth and overall survival. A central finding has been the cross-talk between tumor cells and the surrounding environment or stroma. This tumor stroma, comprised of various cells, and extracellular matrix (ECM), has been shown to aid in suppressing host immune responses against tumor cells. Through immunosuppressive cytokine secretion, metabolic alterations, and other mechanisms, the tumor stroma provides a complex network of safeguards for tumor proliferation. With recent advances in more effective, localized treatment, radiation therapy (XRT) has allowed for strategies that can effectively alter and ablate tumor stromal tissue. This includes promoting immunogenic cell death through tumor antigen release to increasing immune cell trafficking, XRT has a unique advantage against the tumoral immune evasion mechanisms that are orchestrated by stromal cells. Current studies are underway to elucidate pathways within the tumor stroma as potential targets for immunotherapy and chemoradiation. This review summarizes the effects of tumor stroma in tumor immune evasion, explains how XRT may help overcome these effects, with potential combinatorial approaches for future treatment modalities.

Keywords: radiation therapy (radiotherapy), immunotherapy, stroma, cancer, tumor microenvironment

\section{INTRODUCTION}

Cancer therapy has advanced greatly over the past several decades, and recent advances in immunotherapy have led to marked improvement in outcomes and quality of life in patients with cancers previously thought to be incurable $(1,2)$. However, responses to immunotherapy are not as robust as previously hoped. This has led to increased interest in the mechanisms of tumor immune evasion. Increasing observations strongly suggest the tumor microenvironment (TME) and stroma are sources for tumor evasion of the immune system and related immunotherapies.

The stromal microenvironment of a tumor presents an underlying challenge to the efficacy of cancer immunotherapy. In their seminal review, Hanahan and Weinberg named evading immune 
destruction as an emerging hallmark of cancer among other related activities, such as metabolic reprogramming and induction of angiogenesis within the TME (3). For cytotoxic T cells and other immune cells to kill cancer cells, physical cellto-cell contact is necessary (4). However, stromal cells actively orchestrate resistance to antitumor immunity by restricting $\mathrm{T}$ cells from making physical contact with cancer cells (5). The stroma surrounding tumor islets of solid malignancies consists of a myriad of molecular and cellular components: immune cells, including myeloid-derived suppressor cells (MDSCs), tumor-associated macrophages (TAMs), and regulatory $\mathrm{T}$ cells (Tregs); fibroblasts; epithelial cells; extracellular matrix (ECM) proteins; blood and lymphatic vessels; and various metabolites, chemokines, and cytokines.

Leveraging the components of the stromal microenvironment, tumors employ a variety of strategies for immune evasion. These strategies can be broadly grouped thematically into the following categories: immune cell regulation, metabolic reprogramming, and hypoxia. These immune evasion strategies collectively synergize to blunt the efficacy of tumor-infiltrating lymphocytes (TILs) with regard to both activation and infiltration. Clinically, this may significantly limit significant limitation of cancer immunotherapy. Indeed, evidence suggests that baseline infiltration of both $\mathrm{T}$ cells and natural killer cells as well as expression of various chemokines involved in immune cell recruitment to the TME are strongly associated with prognosis for a variety of histological types of cancer (6). Therefore, we believe that the stroma is an underexplored target for immunotherapies that can also synergize with other therapeutic modalities, such as radiation therapy (XRT). Overcoming the immunesuppressive stroma may prove to be integral to unleashing the full potential of immunotherapy and bolstering its antitumor effects.

Radiation therapy is a gold standard of cancer treatment, with more than $50 \%$ of cancer patients needing local therapy with XRT (7). With increasing knowledge of the TME's role in immune evasion, interest in the effect of XRT on the TME is growing. From increasing tumor antigen presentation to facilitating trafficking of $\mathrm{T}$ cells, XRT plays an important immunogenic role in treatment of cancer and its microenvironment. In this review, we describe how the stroma affects antitumor immunity, XRT's role in disrupting the tumor stroma and TME, and future role of XRT combined with immunotherapy to enhance antitumor immunity.

\section{TUMOR STROMA: EVADING THE ANTITUMOR IMMUNE RESPONSE}

\section{Exclusion of Effector Immune Cells From the Tumor Microenvironment}

The most observable effect of the tumor stroma in the context of cancer immunotherapy is the exclusion of $\mathrm{T}$ cells from tumor beds, resulting in a "cold" phenotype. Inflammatory chemokines are the primary factors involved in trafficking and homing of $\mathrm{T}$ cells to the TME. Gene expression profiling performed with a series of melanoma metastases identified six chemokinesCCL2, CCL3, CCL4, CCL5, CXCL9, and CXCL10-that are associated with $\mathrm{CD} 8^{+}$T-cell recruitment and demonstrated that chemokine blockade inhibited migration of $\mathrm{CD}^{+}{ }^{+}$effector T cells in vivo (8). To induce rapid chemotaxis toward inflammatory chemokines, activated $\mathrm{T}$ cells have increased expression of surface chemokine receptors, including CXCR3, which, along with its interferon (IFN)- $\gamma$-inducible ligands, has been associated with a Th1 immune response and accumulation of both $\mathrm{T}$ and natural killer cells in the tumor bed (9-11).

However, tumors commonly dysregulate normal chemokine pathways and express different chemokines, such as nitrosylated CCL2 and CCL28, which result in the recruitment and accumulation of Tregs, TAMs, immature dendritic cells (DCs), and MDSCs and form an immune-suppressive TME (12). TME conditions are partly responsible for such changes in chemokine networks. Nitrosylation of CCL2, which normally supports tumor-infiltrating lymphocyte trafficking into the tumor core, occurs through the production of reactive nitrogen species in the TME (13). CCL28 is produced as a result of tumor hypoxia and the release of damage-associated pattern molecules (14). In addition, tumors often specifically target chemokines that are responsible for cytotoxic $\mathrm{T}$ lymphocyte (CTL) infiltration. One such chemokine is CXCL11, which specifically attracts $\mathrm{CXCR}^{+} \mathrm{CD}^{+}$cells and undergoes proteolytic alterations induced by the tumor, resulting in failure to attract TILs (15). In addition, preclinical and clinical evidence has demonstrated that expression of CCL27, which also plays a role in $\mathrm{T}$ cell homing under inflammatory conditions, is downregulated by hyper-activation of the epidermal growth factor receptor (EGFR)/Ras/mitogen-activated protein kinase (MAPK) signaling pathway in melanoma (16). Overall, manipulation of chemokine networks in the TME results in an abundance of M2 TAMs and other regulatory components that blunt the antitumor activity of CTLs.

In the stroma, both tumor cells and these abundant M2 TAMs secrete various molecules, such as vascular endothelial growth factor (VEGF), interleukin (IL)-10, transforming growth factor (TGF)- $\beta$, adenosine, and prostaglandin $E_{2}$, that inhibit DC activation and maturation and suppress the activity of CTLs and natural killer-mediated immunity (17). For example, the production of VEGF, which is a well-known mediator of angiogenesis, can play a strong role in preventing DC precursors from maturing into DCs (18). Likewise, prostaglandin $\mathrm{E}_{2}$ secretion modulates chemokine production in favor of Tregs and MDSCs differentiation while inhibiting CTLs and natural killer cell populations and decreases production of IL-2 and IL-12 (19). M2 TAMs have immune-suppressive roles that extend beyond the production of soluble factors. The "immune-excluded" phenotype can physically occur via long-lasting interactions between CTLs and TAMs. Peranzoni and colleagues showed that stromal macrophages impede $\mathrm{CD}^{+}{ }^{+} \mathrm{T}$ cells from reaching tumor islets by making long-lasting contacts that reduce T-cell motility (20). Upon pharmacological depletion of TAMs, T-cell infiltration and migration into the tumor islets were no longer impeded, and this enhanced the efficacy of anti-programmed cell death protein 1 (PD-1) immunotherapy (20). Clinically, the same 
study found that lung squamous cell carcinoma patients with high tumor: stroma ratios, which reflected increased $\mathrm{CD} 8^{+} \mathrm{T}$-cell infiltration into tumor islets, had better overall survival than did patients with low ratios (20).

Tumor vasculature may play a strong role in the stromal mechanisms of immune exclusion. The migration of $\mathrm{T}$ cells through the endothelium, which is often dysregulated as a result of vasculature remodeling, is another challenge to antitumor immunity. For $\mathrm{T}$ cells to migrate to the tumor bed, they must adhere to the endothelium (21). However, expression of various endothelial adhesion molecules, such as intercellular adhesion molecule (ICAM)-1 and vascular cell adhesion protein (VCAM)1 , is downregulated in endothelial cells surrounding solid tumors (22). Recently, Motz and colleagues have described a mechanism by which the tumor endothelial barrier regulates $\mathrm{T}$ cell migration into tumors (23). In both human and mouse tumor vasculature, the expression of Fas ligand (FasL), which induces apoptosis, was detected, but it was not detected in normal vasculature (23). Additionally, the expression of FasL on endothelium was associated with decreased $\mathrm{CD} 8^{+}$infiltration and accumulation of Tregs, which were resistant to FasL due to higher c-FLIP expression. However, this blunting of $\mathrm{CD}^{+} \mathrm{T}$ cell infiltration was reversed by pharmacologic inhibition of prostaglandin $E_{2}$ and VEGF, which were shown to cooperatively induce FasL expression on this tumor endothelial "death barrier" (23). The dense stroma matrix architecture also presents a unique challenge to $\mathrm{T}$ cell infiltration, and matrix reduction with collagenase has been shown to improve T cell infiltration $(24,25)$. Finally, cancerassociated fibroblasts (CAFs) in the stroma have pleiotropic roles in secretion of chemokines, cytokines, and metabolites that alter antitumor immunity (26). Molecular strategies to normalize tumor vasculature and induce tertiary lymphoid structures have shown much promise in orchestrating effective $\mathrm{T}$ cell immunotherapy preclinically (27-30). Overall, tumor cells employ a combination of these above mechanisms in excluding cytotoxic T-cells from the tumor microenvironment, blunting anti-tumor immunity (Figure 1).

\section{Metabolic Reprogramming}

Metabolic competition between tumor cells and immune cells is known to cause T-cell anergy and immune resistance. Tumor cells, as well as stromal endothelial cells and CAFs, are characterized by the Warburg effect (31). The Warburg effect is traditionally recognized as a unique type of cancer metabolism described as the switch from oxidative phosphorylation to anaerobic glycolysis in the presence of oxygen (32). Warburg found that cancer cells mainly depend on anaerobic glycolysis survival even in the presence of oxygen, which leads to the substantial depletion of glucose from the TME, causing pleiotropic immuno-suppressive effects (33). Excessive depletion of glucose and essential amino acids such as glutamine, tryptophan, and arginine in the TME, coupled with production of metabolites such as lactate, adenosine, and kynurenine, blunts cytotoxic T-cell function while promoting accumulation of regulatory immune cells, such as Tregs, TAMs, and MDSCs (34). Therefore, altered cancer metabolism of tumor stromal cells is a significant factor that mediates resistance of cancer to immunotherapy.

Many metabolic alterations are driven by the need for $\mathrm{NADPH}$, a unique high-energy molecule that is required for lipid synthesis, a building block for the plasma membrane in rapidly growing tumor cells. In almost all types of cancer, both cancer cells and stromal cells like CAFs overexpress transketolase, an enzyme in the pentose phosphate pathway, which importantly produces NADPH and ribose (35). Transketolase is now considered one of the most universally overexpressed genes in cancer metabolism. Additionally, investigators recently found that patients with isocitrate dehydrogenase 1 (IDH1)-mutant glioblastoma had a better prognosis than IDH1 wild type glioblastoma (36). Interestingly, mutation leads to depletion of elevated NADPH pools in cancer cells. Unlike wild-type isocitrate dehydrogenase 1 , the mutant form found in glioma patients depletes NADPH pools by converting NADPH to $\mathrm{NADP}+$ (37). Multiple studies have implicated the well-known tumor suppressor p53 in regulating metabolic reprogramming. When Ahmad and colleagues induced overexpression of p53 in human prostate cancer cells and combined it with treatment with 2-deoxy-D-glucose, they showed that the cancer cells overexpressing p53 died of oxidative stress by disrupting glucose influx using 2-deoxy-D-glucose, demonstrating a major role for p53 in glucose metabolism major metabolic switch (38). Their work supports the recently identified role of p53 as a metabolic suppressor of NADPH production (39). One of the enzymes controlled by $\mathrm{p} 53$ is malic enzyme, a major NADPH producer in cells (40). Another enzyme whose activity is inhibited by $\mathrm{p} 53$ is glucose-6-phosphate dehydrogenase, which is the first step in the pentose phosphate pathway (39). Targeting of cancer metabolism is a crucial consideration in any therapeutic approach and we will later discuss the role XRT plays in this context.

\section{XRT: CHALLENGING THE TUMOR STROMA AND TME \\ The Evolving Role of XRT in Antitumor Immunity}

The field of radiation biology has historically focused on the effects of radiation in killing cancer cells in isolation. Although the earliest cellular radiobiology experiments yielded significant advances in the understanding of DNA damage and repair, they did not account for the impact that local and systemic factors may have on radiation responses. In vitro clonogenic and colony formation assays, in which radiation log kill curves were first generated, but did not include an understanding of stromal microenvironment and immunity (41). Moreover, in vivo tumor xenograft experiments have historically relied on immunedeficient animal models (42). As such, these classic models that radiation biologists relied on for decades were insufficient to elucidate phenomena such as the abscopal response $(43,44)$ and the efficacy of PD-1-directed therapies (45).

Increasing evidence has implicated the stromal microenvironment as being a critical mediator of radiation responses both locally and systemically. For example, the 


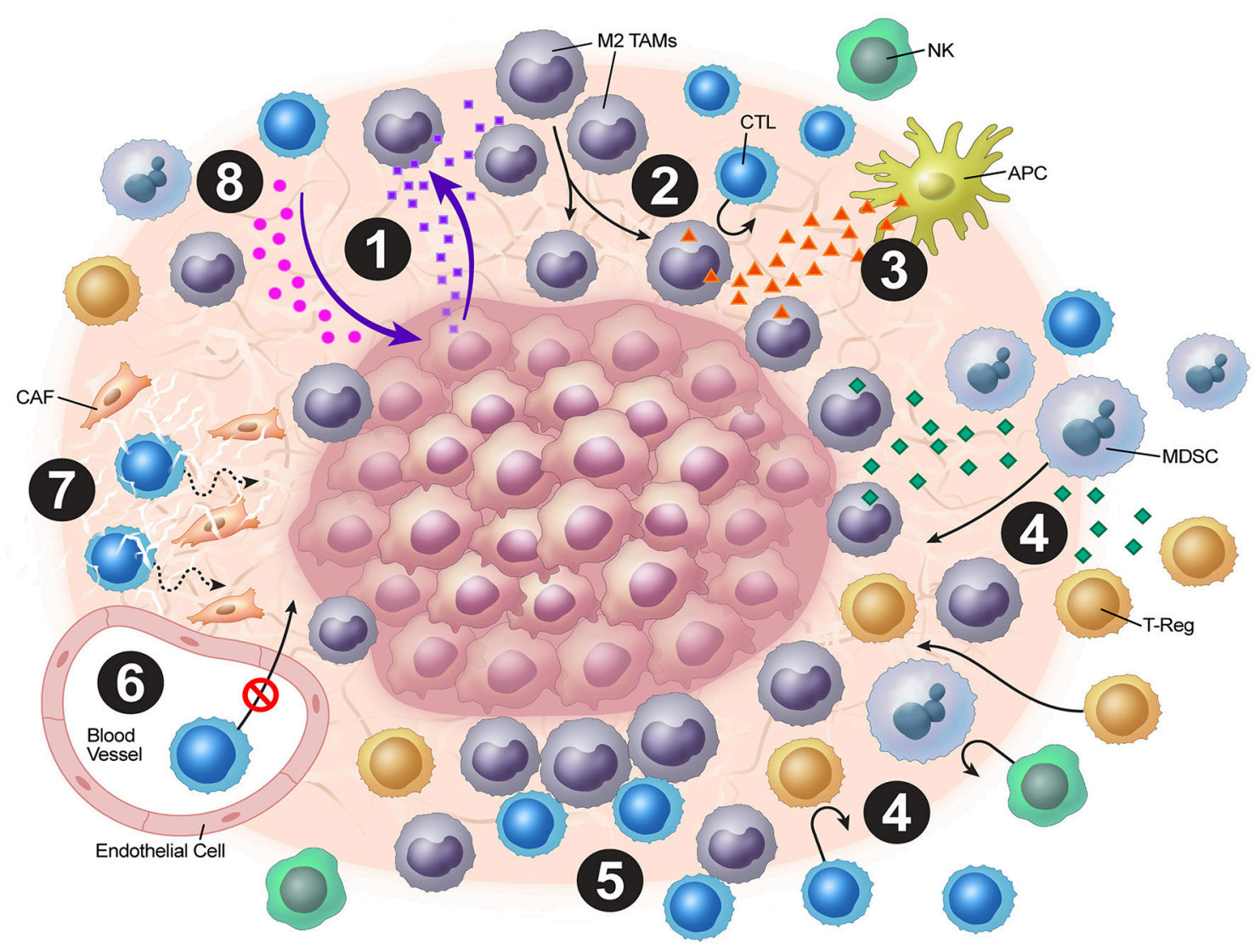

FIGURE 1 | Overview of tumor stromal mechanisms of immune evasion. (1) The tumor stroma disrupts normal chemokine pathways. (2) Chemokine dysregulation leads to increased M2 TAM populations. (3) M2 TAMs release VEGF, which inhibits DC maturation. (4) M2 TAMs also release chemokines and cytokines (e.g. TGF- $\beta$ ), which attract Tregs and MDSCs. (5) Stromal macrophages limit CD8 ${ }^{+}$T-cell infiltration and migration. (6) ICAM and VCAM downregulation lead to decreased CTL penetration. (7) CAFs and the stromal matrix inhibit CTL mobility. (8) Depletion of resources and accumulation of tumor metabolic byproducts leads to blunting of CTL functionality.

observation that COMMA-D cells demonstrate enhanced tumorigenicity when implanted into pre-irradiated fat from murine mammary stroma in vivo underlined the hypothesis that radiation can have differential effects on tumors and the surrounding microenvironment (46). Radiation is a potent inducer of vascular injury, inflammation, and fibrosis. Also, hypoxia and activation of hypoxia-inducible factor-1 $\alpha /$ VEGF signaling as a result of radiation-induced vascular dysfunction can promote radioresistance (47). Furthermore, irradiation sets in motion a robust inflammatory and fibrotic response in stroma mediated by cytokines such as IL-1, IL-6, IL-10, and TGF- $\beta$ that can modify tumor responses to both XRT and chemotherapy (48). Indeed, radiation has a myriad of pleiotropic effects in tumors and their stroma that are only starting to be understood $(49,50)$. With increasing recognition of the fundamental role played by stromal immune signaling in tumor maintenance and radioresistance, pursuing mechanism-based strategies to overcome XRT resistance based on a comprehensive understanding of not only tumor biology but also local stromal and systemic immunobiology is crucial.
Historically, XRT was thought to be primarily immunosuppressive. However, the discovery of the abscopal effect in multiple tumor types (although rare) has significantly altered our understanding of XRT's role in the immune system. This new paradigm demonstrates XRT to be an immunomodulatory tool that facilitates for recruitment and activation of the immune system to fight tumors. The main underpinning of XRT's effect on antitumoral immunity is increasing the release of tumor antigens and their availability for antigen-presenting cells (APCs) to take up and prime $\mathrm{T}$ cells. However, XRT also has direct effects on the surrounding stroma that enables the immune system to increase antitumoral responses.

In addition, a potential strategy involves XRT to eradicate all gross disease followed by immunotherapy to eliminate remaining microscopic disease in cancer patients. Researchers demonstrated the benefit of this strategy in the recent PACIFIC trial (NCT02125461) examining sequential XRT and immunotherapy (51). Antonio et al. recently reported results from this randomized phase 3 study of 713 patients with stage 3 locally advanced, unresectable non-small cell lung 
cancer who received anti-programmed death-ligand 1 antibody, durvalumab, or a placebo after completion of two or more cycles of platinum-based chemoradiation. Recent updated results have demonstrated a markedly longer median progression-free survival (PFS) duration with durvalumab than with the placebo (17.2 vs. 5.6 months) following chemoradiation (52).

We can suggest that XRT and immunotherapy worked synergistically in the PACIFIC trial, in which XRT first ablated all gross disease, leaving behind only microscopic metastases, which immunotherapy controlled. The lack of recurrences in that study, resulting in extended PFS in patients receiving immunotherapy, stems from the enhanced ability of immune cells to infiltrate and eliminate microscopic metastases, which lack a stromal microenvironment but can still seed the growth of larger metastases. Indeed, a study by Zhang and colleagues demonstrated poor prognoses and increased rates of recurrence in non-small cell lung cancer patients with stroma-rich tumors, in whom the tumor: stroma ratio was quantified using hematoxylinstained tissue specimens (53). Therefore, XRT can ablate all gross disease and its stroma to enhance the effects of immunotherapy on remaining microscopic disease with a less dense stromal microenvironment.

\section{Immunogenic Mechanisms of XRT}

The landmark PACIFIC trial suggests significant improvements in patient outcome by utilizing XRT combined with immunotherapy. This will impact many future trial designs for multiple solid tumors with the goal of improving the patient outcomes. As described previously, XRT was initially used for its direct induction of DNA damage, leading to tumor cell death (54). Historically, this DNA death mechanism was seen as immunosuppressive due to the radiosensitivity of lymphocytes (55). However, with recent advances in technology including stereotactic body radiation therapy (SBRT), which allows for tighter dose distributions and higher doses given, there has been increasing evidence that XRT can serve to help activate $\mathrm{T}$ cells and destroy much of the immune inhibitory stroma.

A direct immune-related result of XRT is the release of tumor antigens, which allows for APC presentation and subsequent $\mathrm{CD}^{+}$cell activation. This modality of cell death is termed immunogenic cell death (ICD). Traditionally, apoptosis is considered a tolerogenic process, which limits the ability of the immune system to develop a full response. However, with ICD, an external stress source facilitates the release of danger-associated molecular patterns (DAMPs), which elicit a signal to APCs and instigate cell death (56). Several DAMPs have been implicated in the ICD pathway, such as CRT, HMGB1, and secreted ATP $(57,58)$.

Even with increased antigen release due to XRT leading to increased ICD, the TME does not allow for proper activation of the immune response. For example, tumors have demonstrated downregulated major histocompatibility complex class I (MHCI) expression, which leads to decreased recognition of tumor cells by effector $\mathrm{T}$ cells $(59,60)$. Clinically, increased MHCI expression has been associated with improved survival of multiple cancer types $(61,62)$. Biologically, this makes sense, as an increase in the number of $\mathrm{T}$ cell-mediated reactions can occur, conferring stronger immune responses. The reduced expression of MHC-1, found biologically is found in the tumor stroma can be overcome by XRT. In vitro studies have demonstrated that XRT can upregulate MHC-I expression at sublethal doses (63-66). One underlying mechanism promoting this phenotype occurs through increased peptide availability following XRT and subsequent mammalian target of rapamycin (mTOR) activation, leading to an increase in MHC-I protein subunits in a dosedependent fashion (67). Ultimately, this leads to an increase in effector activity by facilitating proper effector signaling, thereby increasing the overall $\mathrm{T}$-cell repertoire.

Having antigens and the necessary cell-surface receptors alone is not sufficient to overcome all of the negative effects of tumor stroma on the immune system. Activation of pro-inflammatory signals to overcome the immunosuppressive population of Tregs, M2 TAMs, and MDSCs is imperative. XRT has been shown to facilitate this process through several chemokine/cytokine modulations within the TME. Type I IFNs play a role in this process, as they are required for proper DC maturation, increasing MHC-I expression and T-cell priming (68). IFN expression is upregulated by XRT through the cGAS-STING pathway. In this process, cGAS is activated by the DNA damage caused by XRT, with downstream effects leading to production of nuclear factor- $\kappa \mathrm{B}$ and other transcription factors for IFN (69). Indeed, in a recent in vivo study using an anti-PD-1 therapyresistant mouse lung cancer cell line, suppression of type I IFN expression was associated with anti-PD-1 therapy resistance due to reduced MHC-I expression, but tumors became responsive to anti PD-1 therapy after XRT (66).

XRT has also been shown to orchestrate T cell immunotherapy by promoting $\mathrm{T}$-cell homing into the tumor bed through a variety of mechanisms including chemokine expression, macrophage polarization, and expression of adhesion molecules on tumor vasculature. As described previously in this review, the stroma provides signals that prevent trafficking and homing to a tumor using several chemokines. With XRT, these chemokine signals are altered and allow for better lymphocyte "pulling" into the TME. Expression of CXCL16, a chemokine that assists in T-cell infiltration, has been upregulated in breast cancer cells after XRT at 2 fractions at $12 \mathrm{~Gy}$. This allows for increased $\mathrm{CD} 8^{+}$activation of T cells expressing CXCR6 in vivo. Subsequently, loss of CXCR6 results in loss of this phenotype and poor outcomes in vivo (70). Also, immune cell infiltration has occurred with low-dose XRT (2 Gy). Klug et al. demonstrated polarization of M2 TAMs to NOS $^{+}$M1 TAMs after low-dose XRT (71). Moreover, low-dose $\mathrm{XRT}$ can increase T-cell recruitment to pancreatic tumors in vivo.

Adhesion molecules are also altered after XRT. Studies of K562 cells have demonstrated upregulation of VCAM-1 expression in vitro after exposure to 16-20 Gy within $24 \mathrm{~h}$ (72). This upregulation of VCAM-1 has been further observed in other cancer types in vivo after low-dose XRT (73). Upregulation of adhesion molecule expression is not limited to tumor cells, as lymphatic endothelial cells have also demonstrated this change after single doses of XRT (74). Furthermore, ICAM-1 expression is increased in several tumor cell lines after XRT $(75,76)$. Overall, upregulation of these adhesion molecules allows for increased 
infiltration of lymphocytes to tumor cells, increased affinity binding to $\mathrm{CD}^{+}$cells, and ultimately increased immunogenicity.

In a nutshell, XRT leads to neo-antigens and DAMPs release, upregulation of MHC-I, expansion of T-cell repertoire, activation of the STING pathway and production of Type-I interferons, and upregulation of adhesion molecules such as VCAM/ICAM. Additionally, low dose XRT could polarize the M2 macrophages to $\mathrm{M} 1$ and reduce the levels of tumor-induced Tregs. Further work is needed to make conclusions regarding the optimal combinations and timings of XRT with immunotherapy and other targeted treatments to overcome immune resistance that is orchestrated by tumor stroma. The tumor stroma is complex and intricately dynamic with multiples layers of cytokine signaling and XRT provides a much-needed tool to combat such a clinical challenge. We believe the above-mentioned mechanisms of XRT work in concert to elicit systemic anti-tumor responses. In summary, XRT has multiple effects on the tumor stroma to increase anti-tumor immunity (Figure 2).

\section{Targeting Cancer Metabolism}

Based on recent discoveries in the field of cancer metabolism that we discussed previously, researchers have proposed new rationales behind cancer metabolism, providing insight into why XRT and immune therapy are perhaps the best clinically available weapons we have to fight cancer. Very little effort has been directed toward tackling the metabolic aspect of cancer using radiation and addressing targeting of immune metabolism to improve cancer therapies (77). XRT is the only effective established clinical tool that takes advantage of the metabolic aspect of cancer. In their 2005 article, Spitz et al. described that when glucose was deprived from cell media culture, cancer cells died of oxidative stress (78). What they showed was that by shutting off the glucose influx into cancer cells, they were unable to manipulate the metabolic environment to fight oxidative stress, which can be induced by XRT. Later, Coller et al. discussed the importance of protection against reactive oxygen species manifested in patients with abnormal cancer metabolism (79).

As of now, the only available clinical tool to induce oxidative stress is XRT, which works by increasing the amount of reactive oxygen species, such as hydroxyl radical, which causes DNA damage and depletes NADPH pools needed for the proliferation of cancer cells. XRT causes oxidative stress to kill cancer cells by effectively depleting the pool of NADPH, which is rapidly consumed by proliferating cancer cells to support their growth, reduce their levels of oxidized glutathione, or neutralize any oxidative damage they go through. Of note, both endothelial cells and fibroblasts demonstrate upregulation of the glycolytic pathway and pentose phosphate pathways, so these stromal cells would be affected by XRT as well.

\section{XRT LIMITATIONS: STRATIGIES TO OVERCOME RESISTANCE}

Radiation provides strong antitumor immunogenic responses to help overcome the anti-tumor immune evading mechanisms that the TME provides. However, the TME also has mechanisms that help tumors evade the full effects of initial and subsequent rounds of XRT. One important mechanism of this evasion comes from fibrosis after XRT. Fibrosis, which is initiated by the activation of inflammatory pathways, allows for further radioprotection and decreased vascular permeability of tumors which lead to increased resistance to subsequent therapies (50). CAFs are one of the largest cell populations within the tumor stroma that are drivers of stromal proliferation (80). After XRT, these CAFs are further activated. This additional activation enables CAFs to produce several cytokines, proteins, and enzymes to promote stromal expansion $(80,81)$. In vivo studies demonstrated that CAFs can mediate autophagy and irradiated tumor cell recovery through insulin-like growth factor 1-mediated mechanisms (82).

CAFs also produce important proteins such as collagen, fibronectin and integrins. Studies have demonstrated integrins to be of particular interest following XRT. A modest postXRT increase in expressions of both $\alpha$ and $\beta$ integrins within the stroma occurred in vivo $(83,84)$. These integrins help anchor tumors in place as well as initiate integrinspecific signal transduction. These effects lead to and promote chemoradiation resistance of tumors and induce tumor growth for multiple cancer types (85). Mantoni et al. demonstrated this association in pancreatic cancer cases, as cancer cells co-cultured with irradiated fibroblasts demonstrated greater radioresistance and integrin concentration than did their nonirradiated counterparts (86). Integrins are also implicated to have roles in tumor invasion and metastasis (87). Clinically, integrin expression is strongly associated with radioprotection and increased proliferation of breast cancer (88). Mechanistically, how integrins enforce this phenotype has yet to be determined. One in vivo study demonstrated that $\beta_{1}$-integrins produced inhibitory signals in an insulin-like growth factor 1 receptordependent manner in irradiated prostate tumors (84). Another study demonstrated that radioresistance develops in small-cell lung cancer cells through $\beta_{1}$-integrin-mediated phosphatidyl inositol 3-kinase activation (89).

Inhibition of these CAFs is an area of active investigation. Tirosh et al. sought to elucidate genotypic and phenotypic states of melanomas using single-cell RNA sequencing of tumor samples from patients with metastatic disease (90). They found that the enzyme NADPH oxidate 4 (NOX4), is an integral component of fibroblast differentiation and may be a viable target for inhibition of CAF-associated tumor immune evasion. Although multiple phase $1 / 2$ trials have demonstrated CAF inhibitors to be safe, they did not demonstrate improved tumor control or survival in patients with metastatic colorectal or pancreatic cancer (91-93). Notably, none of these trials included patients receiving XRT. In theory, combination of CAF inhibitors with XRT will minimize immunosuppression and maximize anti-tumorigenicity.

Another important aspect of the TME is the presence of Tregs, which suppress immunity through a variety of mechanisms, including TGF- $\beta$ and IL-10 production, IL-2 depletion, and ATP degradation into immunosuppressive adenosine via the ectoenzymes CD39 and CD73 (94). Importantly, Tregs are known to correlate with poor prognosis for various cancer subtypes (95). When a tumor is irradiated, various changes in 


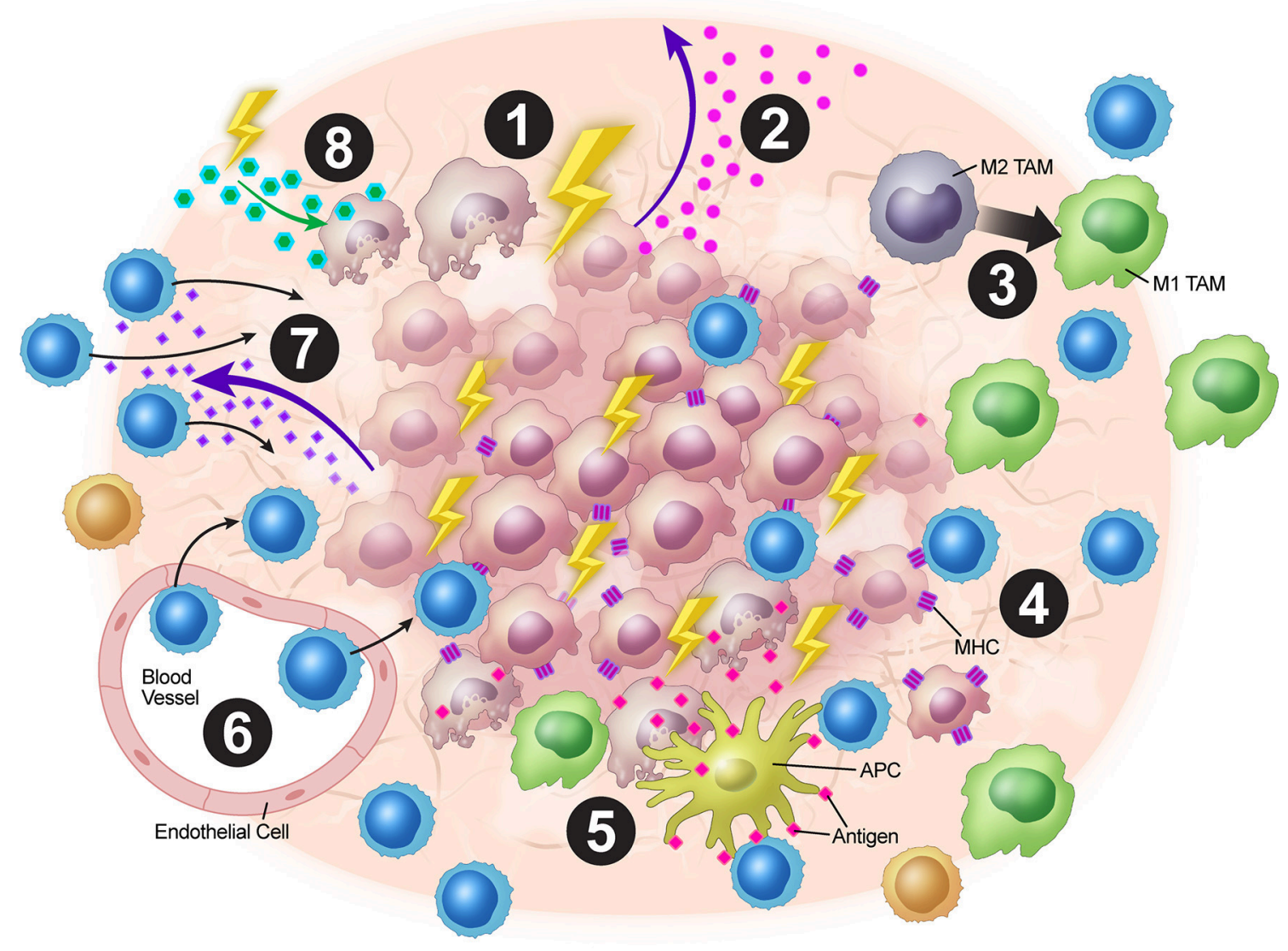

FIGURE 2 | Overview of XRT's effects on the tumor stroma. (1) XRT ablates and reprograms the stroma. (2) Increased STING pathway activation leads to upregulation of type I IFNs. (3) TAMs are polarized from the M2 to the M1 phenotype. (4) Radiation increases MHC-I expression on tumor cells. (5) Tumor destruction leads to increased antigen presentation via ICD. (6) Upregulation of VCAM-1 and ICAM-1 expression leads to increased T-cell adhesion within the stroma. (7) Upregulation of expression of chemokines such as CXCL16 leads to T-cell trafficking into the TME. (8) Radiation alters stromal cell metabolism leading to increased reactive oxygen species and subsequent surrounding cell death due to changes in oxygen requirement.

its Treg population occur. Researchers showed that Tregs appear to be more radioresistant than other subsets of $\mathrm{T}$ cells, thus increasing the prevalence of Tregs at a tumor site $(96,97)$. Muroyama et al. further demonstrated Treg proliferation with increased Ki-67 staining for Tregs after XRT when compared to control (98). In addition, the authors blocked T-cell migration into tumors using fingolimod and saw similar results, suggesting that the Tregs at tumors proliferate. In a different study, 8.5 Gy given five times decreased the population of Tregs and their suppressive capabilities (99). These studies suggest that different doses of radiation can have different effects on the Treg population, with hypofractionation perhaps having more anti-Treg effects than single doses.

Thus, depletion of Tregs in combination with XRT is a logical antitumor strategy. Schoenhals et al. investigated the effects of an IgG2a (depleting isotype) anti-glucocorticoid-induced tumor necrosis factor-related protein (GITR) antibody in an anti-PD-1resistant murine lung adenocarcinoma model (100). They found that the protein was highly expressed at the tumor site, that antiGITR therapy preferentially depleted Tregs at the tumor site, and that combining this therapy with XRT and anti-PD-1 therapy generated a systemic and durable antitumor response. These results highlight the potential of XRT to overcome treatment resistance of cancer, an area of intense interest in the field of cancer immunotherapy.

MDSCs are also are also believed to be among the main drivers of TME immunosuppression, and their presence has been correlated with poor prognosis and response rates for many types of human tumors (101). Studies demonstrated that the frequency of circulating MDSCs was higher with increased tumor burden for multiple solid tumors (101-105). Also, XRT has been shown to inhibit MDSC infiltration into the TME via CCR2 blockade (106). Studies have shown the administration of low-dose gemcitabine depletes MDSCs at low doses in murine models (107). Clinical studies of the safety and efficacy of combined low-dose gemcitabine and antiPD-1 therapy (NCT03302247) are currently underway. Given the synergy between anti-PD-1 therapy and XRT described above, the addition of XRT to this dual therapy may further improve outcomes. 
In addition to these immunosuppressive cells, XRT can impact the fitness of CD8+ effector T cells through cytokines. Interferons have been found to play a role in signaling for $\mathrm{T}$ cell exhaustion through programmed-death ligand 1 (PDL1), which is a member of the B7 superfamily $(68,108)$. One study found IFN $\gamma$ is produced after hypofractionated XRT doses with a subsequent increase in PD-L1 expression in vivo (109). They found that when combined with anti-PD-L1 immunotherapies, $\mathrm{T}$ cells can be rescued from this exhaustive phenotype. Clinically, anti-PD-L1 therapies have recently shown promise, with the ES-SCLC patients demonstrating significant survival benefit with atezolizumab in addition to standardof-care chemotherapy (110). Given this information together, clinical trials with anti-PD-L1 immunotherapy and XRT may bear even more pronounced results.

Hypoxia also poses a challenge for XRT and its ability to ablate tumors and recruit effector immune cells within the TME. MDSCs and TAMs are heavily recruited to these hypoxic environments through various mechanisms, including colony-stimulating factor 1, VEGF, endothelin, and several other proteins (111). Within the tumor stroma, TAMs have plasticity in their phenotype. As noted above, M1 TAMs are characterized as pro-inflammatory and encourage anti-tumoral responses, whereas M2 TAMs are anti-inflammatory and encourage tumor growth. The distribution of these macrophages within the tumor stroma mirrors their stimuli. Specifically, hypoxic conditions promote the tumoral production of IL-4, IL-10, and TGF$\beta$, which promote $\mathrm{M} 2$ polarity and attenuate proper antitumoral immune responses (112). In vivo studies of prostate cancer demonstrated that M2 TAMs which express arginase1 and COX-2 are recruited to these hypoxic centers after irradiation and promote tumor growth $(113,114)$. At higher populations and stronger signaling compared to M1 TAMs and other immunoproliferative cells, these immunosuppressive cells dampen the effector anti-tumor immunity within the stroma after XRT.

Overall, the evidence that XRT modulates the TME and the balance between pro-tumoral and antitumoral signaling is substantial. Investigators have placed an emphasis on how fractionation and dosing play a role in these changes (115, 116). However, from a broader perspective, even with XRT's greater immunogenic capabilities through increased antigen release and ICD, the overall number of cases in which true abscopal effects are seen has been limited (44). Further studies are warranted to evaluate the impact of dosing on these immunogenic characteristics of XRT.

Additionally, the practicality of XRT in the setting of systemic disease is uncertain given increased time demands. For example, the time on the therapy table for each patient per isocenter would increase dramatically. Also, the precision required to target multiple isocenters is not yet possible even with the currently available SBRT technology. Given these practical and mechanistic limitations, our current understanding of XRT as monotherapy for systemic disease is limited. Further studies are warranted to evaluate the timing, dosing, and tolerance of multisite irradiation.

Meanwhile, given the current landscape of multi-agent immunotherapy, such as the combination of anti-PD-1 and antiCTLA- 4 therapy, the body of literature on the synergy of XRT and immunotherapies is rapidly growing (117-119). Targeting immunosuppressive cell populations upregulated by XRT, such as CAFs, Tregs, MDSCs, and TAMs, may further enhance systemic responses to combined XRT-systemic treatment strategies. Future studies must build upon our translational knowledge of these critical relationships to incorporate into clinical trials.

\section{FUTURE CONSIDERATIONS AND GOALS}

The rationale for combining XRT and immunotherapy is clearly apparent based on the aforementioned synergistic mechanisms. This is exemplified by the rapidly increasing number of ongoing prospective trials of combined-modality therapy for cancer (120, 121). Although a few of these are phase 3 studies, most are phase $1 / 2$ trials given little, low-quality evidence of the safety and efficacy of combined immunotherapy and XRT for cancer at various sites (122-125).

The construction of these prospective investigations has several implications for the design of future studies. Although many of the trials in a previous systematic review evaluated concurrent therapy, few specifically evaluated the risks and benefits of this approach with sequential therapy (120). Mechanistically, as described above, delivering XRT prior to immunotherapy has several theoretical benefits, namely regarding antigen presentation, lack of T-cell depletion from concurrent therapy, and modulation of the TME. However, although some data points to a benefit of XRT delivered prior to immunotherapy (126), other data demonstrates better outcomes if both are given concurrently (127) or immunotherapy is followed by XRT (128). Thus, because most of the aforementioned ongoing trials are phase 1 studies, future phase $2 / 3$ work will be dependent on the paradigm put forth by phase 1 data, researchers sincerely hope that future randomized studies directly evaluate the timing of XRT and immunotherapy (e.g., NCT02525757). However, the effect of their timing is likely dependent on the clinical setting, neoplasm, and/or immunotherapeutic agent.

Future studies must also evaluate combinatorial therapy consisting of XRT and multi-agent immunotherapy as well as chemoimmunotherapy. Although a clear concern is that multi-agent immunotherapy may be more toxic than a single agent alone, multi-agent treatment yields better outcomes than do some single agents as noted in the CheckMate 067 metastatic melanoma trial (129). However, whether additional XRT creates unacceptable toxicity with the use of multiple immunotherapeutic compounds is unknown. Likewise, use of chemoimmunotherapy may increase in the future based on the findings of the KEYNOTE-189 trial, which compared chemoimmunotherapy with chemotherapy alone (130). For most disease sites, although delivering concurrent chemoradiation increases the toxicity over that of a single modality alone, the effect of XRT with chemoimmunotherapy remains unknown and must be addressed.

Just as candidate radiosensitizers have been and continue to be developed for XRT, another goal is to explore candidate immunosensitizers that are not immunotherapeutic compounds but rather promote and stimulate the immune system in ways that allow for enhanced immunotherapy effects while 
minimizing complication risks to normal tissues, thereby improving the therapeutic ratio. This is important because excessive immune system "drive" may result in potentially lethal toxic effects. Nevertheless, because the response rate for most immunotherapeutic compounds in seminal clinical trials is about $20 \%$, novel biomolecules are needed to increase this rate $(131,132)$.

Furthermore, the synergy between XRT and immunotherapy may be exemplified by using XRT as a "pseudo-systemic agent" in patients with oligometastatic disease or even widely metastatic disease with good initial responses to chemotherapy and/or immunotherapy (133). Because these patients are expected to survive longer than those with widely disseminated disease, aggressive therapy in them is becoming more reasonable.

Recently, we have seen an increasing trend in the number of positive trials in which XRT is used to treat up to three metastatic sites. Patients with a greater number of metastases would also benefit, but such an approach would be logistically arduous due to the need for multiple isocenters. The development of technologies that make multi-site XRT easier, together with technologies that automate target delineation and treatment planning, such as deep and machine learning, may make XRT more pseudo-systemic in the future, especially when integrating it with other synergistic treatments, such as immunotherapy (134).

\section{CONCLUSIONS}

The stroma is an important component of the TME to study because it has significant implications for limiting antitumor immunity. XRT has long been considered to damage cancer cell DNA, but its effects on the stroma have received little consideration. Given reported evidence, one of

\section{REFERENCES}

1. Hodi FS, O’Day SJ, McDermott DF, Weber RW, Sosman JA, Haanen JB, et al. Improved survival with ipilimumab in patients with metastatic melanoma. $N$ Engl J Med. (2010) 363:711-23. doi: 10.1056/NEJMoa1003466

2. Reck M, Rodriguez-Abreu D, Robinson AG, Hui R, Csoszi T, Fulop $A$, et al. Pembrolizumab versus chemotherapy for PD-L1-positive non-small-cell lung cancer. $N$ Engl J Med. (2016) 375:1823-33. doi: 10.1056/NEJMoa1606774

3. Hanahan D, Weinberg RA. Hallmarks of cancer: the next generation. Cell (2011) 144:646-74. doi: 10.1016/j.cell.2011.02.013

4. Melero I, Rouzaut A, Motz GT, Coukos G. T-cell and NK-cell infiltration into solid tumors: a key limiting factor for efficacious cancer immunotherapy. Cancer Discov. (2014) 4:522-6. doi: 10.1158/2159-8290.CD-13-0985

5. Joyce JA, Fearon DT. T cell exclusion, immune privilege, and the tumor microenvironment. Science (2015) 348:74-80. doi: 10.1126/science.aaa6204

6. Fridman WH, Pages F, Sautes-Fridman C, Galon J. The immune contexture in human tumours: impact on clinical outcome. Nat Rev Cancer (2012) 12:298-306. doi: 10.1038/nrc3245

7. Delaney G, Jacob S, Featherstone C, Barton M. The role of radiotherapy in cancer treatment. Cancer (2005) 104:1129-37. doi: 10.1002/cncr.21324

8. Harlin H, Meng Y, Peterson AC, Zha Y, Tretiakova M, Slingluff C, et al. Chemokine expression in melanoma metastases associated with CD8+ T-cell recruitment. Cancer Res. (2009) 69:3077-85. doi: 10.1158/0008-5472.CAN-08-2281 the greatest benefits of XRT is its ability to eradicate and reprogram the stroma, the same stroma that too often limits the delivery of systemic treatments such as chemotherapy, targeted therapy, immunotherapy, and even cellular therapy. Radiation's ability to eradicate areas of gross disease provides a strong rationale for its use with systemic agents, which would eradicate remaining circulating microscopic disease. Systemic agents are much more effective against the microscopic disease for many reasons, as they no longer face the hypoxic and metabolic changes associated with gross tumor deposits, providing much greater access to target tissues and improving T-cell functionality.

Going forward, we must rationally combine radiation with other stroma-modifying agents, such as colony-stimulating factor 1 receptor, indoleamine 2, 3-dioxygenase 1, and TGF$\beta$ inhibitors, to further exploit these advantages. XRT already provides substantial benefits to patients with localized or oligometastatic disease. Combining XRT with immunotherapy will potentially benefits to patients with more advanced metastatic disease and continue to improve survival.

\section{AUTHOR CONTRIBUTIONS}

All authors contributed to the writing of the manuscript. $\mathrm{HM}$ and RR compiled the first draft of the manuscript in preparation for submission. All authors contributed to revisions and subsequent edits.

\section{ACKNOWLEDGMENTS}

The authors thank Jordan Pietz, MA, CMI, of The University of Texas MD Anderson Cancer Center Department of Creative Communications for assistance with figure illustrations.
9. Wendel M, Galani IE, Suri-Payer E, Cerwenka A. Natural killer cell accumulation in tumors is dependent on IFN-gamma and CXCR3 ligands. Cancer Res. (2008) 68:8437-45. doi: 10.1158/0008-5472.CAN-08-1440

10. $\mathrm{Hu} \mathrm{JK}$, Kagari T, Clingan JM, Matloubian M. Expression of chemokine receptor CXCR3 on T cells affects the balance between effector and memory CD8 T-cell generation. Proc Natl Acad Sci USA. (2011) 108:E118-127. doi: $10.1073 /$ pnas. 1101881108

11. Mikucki ME, Fisher DT, Matsuzaki J, Skitzki JJ, Gaulin NB, Muhitch JB, et al. Non-redundant requirement for CXCR3 signalling during tumoricidal T-cell trafficking across tumour vascular checkpoints. Nat Commun. (2015) 6:7458. doi: $10.1038 /$ ncomms 8458

12. Gabrilovich DI, Ostrand-Rosenberg S, Bronte V. Coordinated regulation of myeloid cells by tumours. Nat Rev Immunol. (2012) 12:253-68. doi: $10.1038 /$ nri3175

13. Molon B, Ugel S, Del Pozzo F, Soldani C, Zilio S, Avella D, et al. Chemokine nitration prevents intratumoral infiltration of antigen-specific T cells. J Exp Med. (2011) 208:1949-62. doi: 10.1084/jem.20101956

14. Facciabene A, Peng X, Hagemann IS, Balint K, Barchetti A, Wang LP, et al. Tumour hypoxia promotes tolerance and angiogenesis via CCL28 and T(reg) cells. Nature (2011) 475:226-30. doi: 10.1038/nature10169

15. Proost P, Mortier A, Loos T, Vandercappellen J, Gouwy M, Ronsse I, et al. Proteolytic processing of CXCL11 by CD13/aminopeptidase $\mathrm{N}$ impairs CXCR3 and CXCR7 binding and signaling and reduces lymphocyte and endothelial cell migration. Blood (2007) 110:37-44. doi: 10.1182/blood-2006-10-049072 
16. Pivarcsi A, Muller A, Hippe A, Rieker J, van Lierop A, Steinhoff M, et al. Tumor immune escape by the loss of homeostatic chemokine expression. Proc Natl Acad Sci USA. (2007) 104:19055-60. doi: 10.1073/pnas.0705673104

17. Lanitis E, Dangaj D, Irving M, and Coukos G. Mechanisms regulating T-cell infiltration and activity in solid tumors. Ann Oncol. (2017) 28(Suppl. 12), xii18-xii32. doi: 10.1093/annonc/mdx238

18. Gabrilovich DI, Chen HL, Girgis KR, Cunningham HT, Meny GM, Nadaf $\mathrm{S}$, et al. Production of vascular endothelial growth factor by human tumors inhibits the functional maturation of dendritic cells. Nat Med. (1996) 2:1096-103.

19. Kalinski P. Regulation of immune responses by prostaglandin E2. J Immunol. (2012) 188:21-8. doi: 10.4049/jimmunol.1101029

20. Peranzoni E, Lemoine J, Vimeux L, Feuillet V, Barrin S, Kantari-Mimoun C, et al. Macrophages impede CD8 T cells from reaching tumor cells and limit the efficacy of anti-PD-1 treatment. Proc Natl Acad Sci USA. (2018) 115:E4041-50. doi: 10.1073/pnas.1720948115

21. Butcher EC, Picker LJ. Lymphocyte homing and homeostasis. Science (1996) 272:60-6.

22. Griffioen AW, Damen CA, Martinotti S, Blijham GH, Groenewegen G. Endothelial intercellular adhesion molecule-1 expression is suppressed in human malignancies: the role of angiogenic factors. Cancer Res. (1996) 56:1111-7.

23. Motz GT, Santoro SP, Wang LP, Garrabrant T, Lastra RR, Hagemann IS, et al. Tumor endothelium FasL establishes a selective immune barrier promoting tolerance in tumors. Nat Med. (2014) 20:607-15. doi: 10.1038/nm.3541

24. Salmon H, Franciszkiewicz K, Damotte D, Dieu-Nosjean MC, Validire P, Trautmann A, et al. Matrix architecture defines the preferential localization and migration of T cells into the stroma of human lung tumors. J Clin Invest. (2012) 122:899-910. doi: 10.1172/JCI45817

25. Bougherara H, Mansuet-Lupo A, Alifano M, Ngo C, Damotte D, Le Frere-Belda MA, et al. Real-Time Imaging of Resident $\mathrm{T}$ Cells in human lung and ovarian carcinomas reveals how different tumor microenvironments control T lymphocyte migration. Front Immunol. (2015) 6:500. doi: 10.3389/fimmu.2015.00500

26. Ziani L, Chouaib S, Thiery J. Alteration of the antitumor immune response by cancer-associated fibroblasts. Front Immunol. (2018) 9:414. doi: 10.3389/fimmu.2018.00414

27. Hamzah J, Jugold M, Kiessling F, Rigby P, Manzur M, Marti HH, et al. Vascular normalization in Rgs5-deficient tumours promotes immune destruction. Nature (2008) 453:410. doi: 10.1038/nature06868

28. Johansson A, Hamzah J, Ganss R. More than a scaffold: Stromal modulation of tumor immunity. Biochim Biophys Acta (2016) 1865:3-13. doi: 10.1016/j.bbcan.2015.06.001

29. Johansson-Percival A, He B, Li Z-J, Kjellén A, Russell K, Li J, et al. De novo induction of intratumoral lymphoid structures and vessel normalization enhances immunotherapy in resistant tumors. Nat Immunol. (2017) 18:1207. doi: $10.1038 /$ ni.3836

30. Johansson-Percival A, He B, Ganss R. Immunomodulation of tumor vessels: it takes two to tango. Trends Immunol. (2018) 39:801-14. doi: 10.1016/j.it.2018.08.001

31. Ghesquiere B, Wong BW, Kuchnio A, Carmeliet P. Metabolism of stromal and immune cells in health and disease. Nature (2014) 511:167-76. doi: $10.1038 /$ nature 13312

32. Warburg O. On the origin of cancer cells. Science (1956) 123:309

33. Ramapriyan R, Caetano MS, Barsoumian HB, Mafra ACP, Zambalde $\mathrm{EP}$, Menon $\mathrm{H}$, et al. Altered cancer metabolism in mechanisms of immunotherapy resistance. Pharmacol Therapeut. (2018). doi: 10.1016/j.pharmthera.2018.11.004. [Epub ahead of print].

34. Renner K, Singer K, Koehl GE, Geissler EK, Peter K, Siska PJ, et al. Metabolic Hallmarks of tumor and immune cells in the tumor microenvironment. Front Immunol. (2017) 8:248. doi: 10.3389/fimmu.2017.00248

35. Xu IM, Lai RK, Lin SH, Tse AP, Chiu DK, Koh HY, et al. Transketolase counteracts oxidative stress to drive cancer development. Proc Natl Acad Sci USA. (2016) 113:E725-734. doi: 10.1073/pnas.15087 79113

36. Dimitrov L, Hong CS, Yang C, Zhuang Z, Heiss JD. New developments in the pathogenesis and therapeutic targeting of the IDH1 mutation in glioma. Int $J$ Med Sci. (2015) 12:201-13. doi: 10.7150/ijms. 11047

37. Maus A, Peters GJ. Erratum to: Glutamate and alpha-ketoglutarate: key players in glioma metabolism. Amino Acids (2017) 49:1143. doi: 10.1007/s00726-017-2414-5

38. Ahmad IM, Abdalla MY, Aykin-Burns N, Simons AL, Oberley LW, Domann $\mathrm{FE}$, et al. 2-Deoxyglucose combined with wild-type p53 overexpression enhances cytotoxicity in human prostate cancer cells via oxidative stress. Free Radic Biol Med. (2008) 44:826-34. doi: 10.1016/j.freeradbiomed.2007.11.007

39. Jiang $\mathrm{P}, \mathrm{Du} \mathrm{W}$, Wang $\mathrm{X}$, Mancuso $\mathrm{A}$, Gao $\mathrm{X}, \mathrm{Wu} \mathrm{M}$, et al. p53 regulates biosynthesis through direct inactivation of glucose-6-phosphate dehydrogenase. Nat Cell Biol. (2011) 13:310-6. doi: 10.1038/ncb2172

40. Jiang P, Du W, Mancuso A, Wellen KE, Yang X. Reciprocal regulation of p53 and malic enzymes modulates metabolism and senescence. Nature (2013) 493:689-93. doi: 10.1038/nature11776

41. Thames HDJr, Withers HR. Test of equal effect per fraction and estimation of initial clonogen number in microcolony assays of survival after fractionated irradiation. Br J Radiol. (1980) 53:1071-7. doi: 10.1259/0007-1285-53-635-1071

42. Steel GG, Courtenay VD, Peckham MJ. The response to chemotherapy of a variety of human tumour xenografts. Br J Cancer (1983) 47:1-13.

43. Hiniker SM, Chen DS, Knox SJ. Abscopal effect in a patient with melanoma. N Engl J Med. (2012) 366:2035-2036. doi: 10.1056/NEJMc1203984

44. Abuodeh Y, Venkat P, Kim S. Systematic review of case reports on the abscopal effect. Curr Probl Cancer (2016) 40:25-37. doi: 10.1016/j.currproblcancer.2015.10.001

45. Topalian SL, Hodi FS, Brahmer JR, Gettinger SN, Smith DC, McDermott DF, et al. Safety, activity, and immune correlates of anti-PD-1 antibody in cancer. N Engl J Med. (2012) 366:2443-54. doi: 10.1056/NEJMoa1200690

46. Barcellos-Hoff MH, Ravani SA. Irradiated mammary gland stroma promotes the expression of tumorigenic potential by unirradiated epithelial cells. Cancer Res (2000) 60:1254-60.

47. Kioi M, Vogel H, Schultz G, Hoffman RM, Harsh GR, Brown JM. Inhibition of vasculogenesis, but not angiogenesis, prevents the recurrence of glioblastoma after irradiation in mice. J Clin Invest. (2010) 120:694-705. doi: 10.1172/JCI40283

48. Lin WW, Karin M. A cytokine-mediated link between innate immunity, inflammation, and cancer. J Clin Invest. (2007) 117:1175-83. doi: 10.1172/JCI31537

49. Barker HE, Paget JT, Khan AA, Harrington KJ. The tumour microenvironment after radiotherapy: mechanisms of resistance and recurrence. Nat Rev Cancer (2015) 15:409-25. doi: 10.1038/nrc3958

50. Valkenburg KC, de Groot AE, Pienta KJ. Targeting the tumour stroma to improve cancer therapy. Nat Rev Clin Oncol. (2018) 15:366-81. doi: 10.1038/s41571-018-0007-1

51. Antonia SJ, Villegas A, Daniel D, Vicente D, Murakami S, Hui R, et al. Durvalumab after Chemoradiotherapy in Stage III non-small-cell lung cancer. N Engl J Med. (2017) 377:1919-29. doi: 10.1056/NEJMoa1709937

52. Antonia SJ, Villegas A, Daniel D, Vicente D, Murakami S, Hui R, et al. Overall survival with durvalumab after chemoradiotherapy in stage III NSCLC. N Engl J Med. (2018) 379:2342-50. doi: 10.1056/NEJMoa1 809697

53. Zhang T, Xu J, Shen H, Dong W, Ni Y, Du J. Tumor-stroma ratio is an independent predictor for survival in NSCLC. Int J Clin Exp Pathol. (2015) 8:11348-55.

54. Bernier J, Hall EJ, Giaccia A. Radiation oncology: a century of achievements. Nat Rev Cancer (2004) 4:737-47. doi: 10.1038/nrc1451

55. Trowell OA. The sensitivity of lymphocytes to ionising radiation. J Pathol Bacteriol. (1952) 64:687-704. doi: 10.1002/path.1700640403

56. Kepp O, Senovilla L, Kroemer G. Immunogenic cell death inducers as anticancer agents. Oncotarget (2014) 5:5190-1. doi: 10.18632/oncotarget.2266

57. Hernandez C, Huebener P, Schwabe RF. Damage-associated molecular patterns in cancer: A double-edged sword. Oncogene (2016) 35:5931-41. doi: 10.1038/onc.2016.104

58. Wu Q, Allouch A, Martins I, Brenner C, Modjtahedi N, Deutsch E, et al. modulating both tumor cell death and innate immunity is essential for 
improving radiation therapy effectiveness. Front Immunol. (2017) 8:613. doi: 10.3389/fimmu.2017.00613

59. Festenstein H, Garrido F. Tumour immunology: MHC antigens and malignancy. Nature (1986) 322:502. doi: 10.1038/322502a0

60. Garcia-Lora A, Algarra I, Garrido F. MHC class I antigens, immune surveillance, and tumor immune escape. J Cell Physiol. (2003) 195:346-55. doi: $10.1002 /$ jcp. 10290

61. Turcotte S, Katz SC, Shia J, Jarnagin WR, Kingham TP, Allen P, et al. Tumor MHC class I expression improves the prognostic value of $\mathrm{T}$ cell density in resected colorectal liver metastases. Cancer Immunol Res. (2014) 2:530-7. doi: 10.1158/2326-6066.CIR-13-0180

62. Goeppert B, Frauenschuh L, Zucknick M, Roessler S, Mehrabi A, Hafezi M, et al. Major histocompatibility complex class I expression impacts on patient survival and type and density of immune cells in biliary tract cancer. $\mathrm{Br} \mathrm{J}$ Cancer (2015) 113:1343-9. doi: 10.1038/bjc.2015.337

63. Santin AD, Hermonat PL, Hiserodt JC, Chiriva-Internati M, Woodliff J, Theus JW, et al. Effects of irradiation on the expression of major histocompatibility complex class I antigen and adhesion costimulation molecules ICAM-1 in human cervical cancer. Int J Radiat Oncol Biol Phys. (1997) 39:737-42. doi: 10.1016/S0360-3016(97)00372-6

64. Garnett CT, Palena C, Chakarborty M, Tsang K-Y, Schlom J, Hodge JW. Sublethal Irradiation of human tumor cells modulates phenotype resulting in enhanced killing by cytotoxic T Lymphocytes. Cancer Res. (2004) 64:7985. doi: 10.1158/0008-5472.CAN-04-1525

65. Wan S, Pestka S, Jubin RG, Lyu YL, Tsai Y-C, Liu LF. Chemotherapeutics and Radiation Stimulate MHC Class I Expression through Elevated Interferon-beta Signaling in breast cancer cells. PLoS ONE (2012) 7:e32542. doi: 10.1371/journal.pone.00 32542

66. Wang X, Schoenhals JE, Valdecanas DR, Li A, Ye H, Zhang F, et al. Suppression of major histocompatibility complex (MHC) class i and ii mediates resistance to anti-PD-1 in lung adenocarcinoma tumors that can be overcome by radiation therapy. Int J Radiat Oncol Biol Phys. (2016) 96(Suppl. 2) S89. doi: 10.1016/j.ijrobp.2016.06.224

67. Reits EA, Hodge JW, Herberts CA, Groothuis TA, Chakraborty MK, Wansley EK, et al. Radiation modulates the peptide repertoire, enhances MHC class I expression, and induces successful antitumor immunotherapy. J Exp Med. (2006) 203:1259-71. doi: 10.1084/jem.200 52494

68. Burnette B, Liang H, Lee Y, Chlewicki L, Khodarev NN, Weichselbaum RR, et al. The Efficacy of radiotherapy relies upon induction of type i interferondependent innate and adaptive immunity. Cancer Res. (2011) 71:2488-96. doi: 10.1158/0008-5472.CAN-10-2820

69. Chen Q, Sun L, Chen ZJ. Regulation and function of the cGASSTING pathway of cytosolic DNA sensing. Nat Immunol. (2016) 17:1142. doi: $10.1038 /$ ni. 3558

70. Matsumura S, Wang B, Kawashima N, Braunstein S, Badura M, Cameron TO, et al. Radiation-induced CXCL16 release by breast cancer cells attracts effector T cells. J Immunol. (2008) 181:3099-107. doi: 10.4049/jimmunol.181.5.3099

71. Klug F, Prakash H, Huber PE, Seibel T, Bender N, Halama N, et al. Lowdose irradiation programs macrophage differentiation to an iNOS(+)/M1 phenotype that orchestrates effective $\mathrm{T}$ cell immunotherapy. Cancer Cell (2013) 24:589-602. doi: 10.1016/j.ccr.2013.09.014

72. Zamai L, Rana R, Mazzotti G, Centurione L, Di Pietro R, Vitale M. Lymphocyte binding to K562 cells: effect of target cell irradiation and correlation with ICAM-1 and LFA-3 expression. Eur J Histochem. (1994) 38 (Suppl 1):53-60.

73. Lugade AA, Moran JP, Gerber SA, Rose RC, Frelinger JG, Lord EM. Local radiation therapy of b16 melanoma tumors increases the generation of tumor antigen-specific effector cells that traffic to the tumor. J Immunol. (2005) 174:7516-23. doi: 10.4049/jimmunol.174.12.7516

74. Rodriguez-Ruiz ME, Garasa S, Rodriguez I, Solorzano JL, Barbes B, Yanguas A, et al. Intercellular adhesion molecule-1 and vascular cell adhesion molecule are induced by ionizing radiation on lymphatic endothelium. Int $J$ Radiat Oncol Biol Phys. (2017) 97:389-400. doi: 10.1016/j.ijrobp.2016.10.043

75. Behrends U, Eißner G, Bornkamm GW, Peter RU, HintermeierKnabe R, et al. Ionizing radiation induces human intercellular adhesion molecule-1 in vitro. J Invest Dermatol. (1994) 103:726-30. doi: 10.1111/1523-1747.ep12398607

76. Chiriva-Internati M, Grizzi F, Pinkston J, John Morrow K, D’Cunha N, Frezza EE, et al. Gamma-radiation upregulates MHC class I/II and ICAMI molecules in multiple myeloma cell lines and primary tumors. Vitro Cell Dev Biol Anim. (2006) 42:89-95. doi: 10.1290/0508054.1

77. Beezhold K, Byersdorfer CA. Targeting immuno-metabolism to improve anti-cancer therapies. Cancer Lett. (2018) 414:127-35. doi: 10.1016/j.canlet.2017.11.005

78. Ahmad IM, Aykin-Burns N, Sim JE, Walsh SA, Higashikubo R, Buettner GR, et al. Mitochondrial $\mathrm{O}^{*}$ - and $\mathrm{H} 2 \mathrm{O} 2$ mediate glucose deprivationinduced stress in human cancer cells. J Biol Chem. (2005) 280:4254-63. doi: 10.1074/jbc.M411662200

79. Coller HA. Is cancer a metabolic disease? Am J Pathol. (2014) 184:4-17. doi: 10.1016/j.ajpath.2013.07.035

80. Cordes $\mathrm{N}$, Meineke V. Integrin signalling and the cellular response to ionizing radiation. J Mol Histol. (2004) 35:327-37. doi: 10.1023/B:HIJO.0000032364.43566.3a

81. Augsten M. Cancer-associated fibroblasts as another polarized cell type of the tumor microenvironment. Front Oncol. (2014) 4:62. doi: $10.3389 /$ fonc. 2014.00062

82. Wang Y, Gan G, Wang B, Wu J, Cao Y, Zhu D, et al. Cancer-associated fibroblasts promote irradiated cancer cell recovery through autophagy. EBioMedicine (2017) 17:45-56. doi: 10.1016/j.ebiom.2017.02.019

83. Nam JM, Onodera Y, Bissell MJ, Park CC. Breast cancer cells in threedimensional culture display an enhanced radioresponse after coordinate targeting of integrin alpha5betal and fibronectin. Cancer Res. (2010) 70:5238-48. doi: 10.1158/0008-5472.CAN-09-2319

84. Goel HL, Sayeed A, Breen M, Zarif MJ, Garlick DS, Leav I, et al. $\beta(1)$ integrins mediate resistance to ionizing radiation in vivo by inhibiting $\mathrm{c}$-Jun amino terminal kinase 1. J Cell Physiol. (2013) 228:1601-9. doi: 10.1002/jcp.24323

85. Cordes N. Integrin-mediated cell-matrix interactions for prosurvival and antiapoptotic signaling after genotoxic injury. Cancer Lett. (2006) 242:11-9. doi: 10.1016/j.canlet.2005.12.004

86. Mantoni TS, Lunardi S, Al-Assar O, Masamune A, Brunner TB. Pancreatic stellate cells radioprotect pancreatic cancer cells through beta1-integrin signaling. Cancer Res. (2011) 71:3453-8. doi: 10.1158/0008-5472.CAN-10-1633

87. Ohuchida K, Mizumoto K, Murakami M, Qian LW, Sato N, Nagai E, et al. Radiation to stromal fibroblasts increases invasiveness of pancreatic cancer cells through tumor-stromal interactions. Cancer Res. (2004) 64:3215-22. doi: 10.1158/0008-5472.CAN-03-2464

88. Yao ES, Zhang H, Chen YY, Lee B, Chew K, Moore D, et al. Increased beta1 integrin is associated with decreased survival in invasive breast cancer. Cancer Res. (2007) 67:659-64. doi: 10.1158/0008-5472.CAN-06-2768

89. Hodkinson PS, Elliott T, Wong WS, Rintoul RC, Mackinnon AC, Haslett C, et al. ECM overrides DNA damage-induced cell cycle arrest and apoptosis in small-cell lung cancer cells through betal integrin-dependent activation of PI3-kinase. Cell Death Differ. (2006) 13:1776-88. doi: 10.1038/sj.cdd.4401849

90. Tirosh I, Izar B, Prakadan SM, Wadsworth, MH II, Treacy D, Trombetta JJ, et al. Dissecting the multicellular ecosystem of metastatic melanoma by single-cell RNA-seq. Science (2016) 352, 189-196. doi: $10.1126 /$ science.aad0501

91. Hofheinz RD, al-Batran SE, Hartmann F, Hartung G, Jager D, Renner $\mathrm{C}$, et al. Stromal antigen targeting by a humanised monoclonal antibody: an early phase II trial of sibrotuzumab in patients with metastatic colorectal cancer. Onkologie (2003) 26:44-8. doi: 10.1159/0000 69863

92. Narra K, Mullins SR, Lee HO, Strzemkowski-Brun B, Magalong K, Christiansen VJ, et al. Phase II trial of single agent Val-boroPro (Talabostat) inhibiting fibroblast activation protein in patients with metastatic colorectal cancer. Cancer Biol Ther. (2007) 6:1691-9. doi: $10.4161 /$ cbt.6.11.4874

93. Catenacci DV, Junttila MR, Karrison T, Bahary N, Horiba MN, Nattam SR, et al. Randomized Phase Ib/II study of gemcitabine plus placebo or vismodegib, a hedgehog pathway inhibitor, in patients with metastatic pancreatic cancer. J Clin Oncol. (2015) 33:4284-92. doi: 10.1200/JCO.2015.62.8719 
94. Plitas G, Rudensky AY. Regulatory T cells: differentiation and function. Cancer Immunol Res. (2016) 4:721-5. doi: 10.1158/2326-6066.CIR-16-0193

95. Ladoire S, Martin F, Ghiringhelli F. Prognostic role of FOXP3+ regulatory T cells infiltrating human carcinomas: the paradox of colorectal cancer. Cancer Immunol Immunother. (2011) 60:909-18. doi: 10.1007/s00262-011-1046-y

96. Qu Y, Jin S, Zhang A, Zhang B, Shi X, Wang J, et al. Gamma-ray resistance of regulatory CD4+CD25+Foxp3+ T cells in mice. Radiat Res. (2010) 173:148-57. doi: 10.1667/RR0978.1

97. Balogh A, Persa E, Bogdandi EN, Benedek A, Hegyesi H, Safrany G, et al. The effect of ionizing radiation on the homeostasis and functional integrity of murine splenic regulatory T cells. Inflamm Res. (2013) 62:201-12. doi: 10.1007/s00011-012-0567-y

98. Muroyama Y, Nirschl TR, Kochel CM, Lopez-Bujanda Z, Theodros D, Mao W, et al. Stereotactic radiotherapy increases functionally suppressive regulatory $\mathrm{T}$ cells in the tumor microenvironment. Cancer Immunol Res. (2017) 5:992-1004. doi: 10.1158/2326-6066.CIR17-0040

99. Wei S, Egenti MU, Teitz-Tennenbaum S, Zou W, Chang AE. Effects of tumor irradiation on host T-regulatory cells and systemic immunity in the context of adoptive T-cell therapy in mice. J Immunother. (2013) 36:124-32. doi: 10.1097/CJI.0b013e31828298e6

100. Schoenhals JE, Cushman TR, Barsoumian HB, Li A, Cadena AP, Niknam S, et al. Anti-glucocorticoid-induced tumor necrosis factorrelated protein (GITR) therapy overcomes radiation-induced treg immunosuppression and drives abscopal effects. Front Immunol. (2018) 9:2170. doi: 10.3389/fimmu.2018.02170

101. Fleming $\mathrm{V}, \mathrm{Hu} \mathrm{X}$, Weber $\mathrm{R}$, Nagibin V, Groth C, Altevogt $\mathrm{P}$, et al. Targeting Myeloid-derived suppressor cells to bypass tumorinduced immunosuppression. Front Immunol. (2018) 9:398. doi: 10.3389/fimmu.2018.00398

102. Almand B, Clark JI, Nikitina E, van Beynen J, English NR, Knight SC, et al. Increased production of immature myeloid cells in cancer patients: a mechanism of immunosuppression in cancer. J Immunol. (2001) 166:678-89. doi: 10.4049/jimmunol.166.1.678

103. Gabitass RF, Annels NE, Stocken DD, Pandha HA, Middleton GW. Elevated myeloid-derived suppressor cells in pancreatic, esophageal and gastric cancer are an independent prognostic factor and are associated with significant elevation of the Th2 cytokine interleukin-13. Cancer Immunol Immunother. (2011) 60:1419-30. doi: 10.1007/s00262-011-1028-0

104. Eruslanov E, Neuberger M, Daurkin I, Perrin GQ, Algood C, Dahm P, et al. Circulating and tumor-infiltrating myeloid cell subsets in patients with bladder cancer. Int J Cancer (2012) 130:1109-19. doi: 10.1002/ijc. 26123

105. Jiang H, Gebhardt C, Umansky L, Beckhove P, Schulze TJ, Utikal $\mathrm{J}$, et al. Elevated chronic inflammatory factors and myeloidderived suppressor cells indicate poor prognosis in advanced melanoma patients. Int J Cancer (2015) 136:2352-60. doi: 10.1002/ijc. 29297

106. Liang H, Deng L, Hou Y, Meng X, Huang X, Rao E, et al. Host STINGdependent MDSC mobilization drives extrinsic radiation resistance. Nat Commun. (2017) 8:1736. doi: 10.1038/s41467-017-01566-5

107. Suzuki E, Kapoor V, Jassar AS, Kaiser LR, Albelda SM. Gemcitabine selectively eliminates splenic Gr-1+/CD11b + myeloid suppressor cells in tumor-bearing animals and enhances antitumor immune activity. Clin Cancer Res. (2005) 11:6713-21. doi: 10.1158/1078-0432.CCR-05-0883

108. Dong H, Strome SE, Salomao DR, Tamura H, Hirano F, Flies DB, et al. Tumor-associated B7-H1 promotes T-cell apoptosis: a potential mechanism of immune evasion. Nat Med. (2002) 8:793. doi: 10.1038/nm730

109. Dovedi SJ, Adlard AL, Lipowska-Bhalla G, McKenna C, Jones S, Cheadle EJ, et al. Acquired resistance to fractionated radiotherapy can be overcome by concurrent PD-L1 blockade. Cancer Res. (2014) 74:5458. doi: 10.1158/0008-5472.CAN-14-1258

110. Horn L, Mansfield AS, Szczesna A, Havel L, Krzakowski M, Hochmair MJ, et al. First-Line atezolizumab plus chemotherapy in extensive-stage smallcell lung cancer. N Engl J Med. (2018) 379:2220-9. doi: 10.1056/NEJMoa18 09064
111. Murdoch C, Giannoudis A, Lewis CE. Mechanisms regulating the recruitment of macrophages into hypoxic areas of tumors and other ischemic tissues. Blood (2004) 104:2224-34. doi: 10.1182/blood-2004-03-1109

112. Mantovani A, Sozzani S, Locati M, Allavena P, Sica A. Macrophage polarization: tumor-associated macrophages as a paradigm for polarized M2 mononuclear phagocytes. Trends Immunol. (2002) 23:549-55. doi: 10.1016/S1471-4906(02)02302-5

113. Tsai CS, Chen FH, Wang CC, Huang HL, Jung SM, Wu CJ, et al. Macrophages from irradiated tumors express higher levels of iNOS, arginaseI and COX-2, and promote tumor growth. Int J Radiat Oncol Biol Phys. (2007) 68:499-507. doi: 10.1016/j.ijrobp.2007.01.041

114. Chen FH, Chiang CS, Wang CC, Tsai CS, Jung SM, Lee CC, et al. Radiotherapy decreases vascular density and causes hypoxia with macrophage aggregation in TRAMP-C1 prostate tumors. Clin Cancer Res. (2009) 15:1721-9. doi: 10.1158/1078-0432.CCR-08-1471

115. Battaglia A, Buzzonetti A, Martinelli E, Fanelli M, Petrillo M, Ferrandina $\mathrm{G}$, et al. Selective changes in the immune profile of tumor-draining lymph nodes after different neoadjuvant chemoradiation regimens for locally advanced cervical cancer. Int J Radiat Oncol Biol Phys. (2010) 76:1546-53. doi: 10.1016/j.ijrobp.2009.10.014

116. Schaue D, Ratikan JA, Iwamoto KS, McBride WH. Maximizing tumor immunity with fractionated radiation. Int J Radiat Oncol Biol Phys. (2012) 83:1306-10. doi: 10.1016/j.jijrobp.2011.09.049

117. Seyedin SN, Schoenhals JE, Lee DA, Cortez MA, Wang X, Niknam S, et al. Strategies for combining immunotherapy with radiation for anticancer therapy. Immunotherapy (2015) 7:967-80. doi: 10.2217/imt.15.65

118. Schoenhals JE, Seyedin SN, Tang C, Cortez MA, Niknam S, Tsouko E, et al. Preclinical Rationale and clinical considerations for radiotherapy plus immunotherapy: going beyond local control. Cancer J. (2016) 22:130-7. doi: $10.1097 / \mathrm{PPO} .0000000000000181$

119. Cushman TR, Gomez D, Kumar R, Likacheva A, Chang JY, Cadena $\mathrm{AP}$, et al. Combining radiation plus immunotherapy to improve systemic immune response. J Thorac Dis. (2018) 10(Suppl. 3), S468-79. doi: $10.21037 /$ jtd.2018.01.130

120. Kang J, Demaria S, Formenti S. Current clinical trials testing the combination of immunotherapy with radiotherapy. J Immunother Cancer (2016) 4:51. doi: 10.1186/s40425-016-0156-7

121. Cushman TR, Caetano MS, Welsh JW, Verma V. Overview of ongoing clinical trials investigating combined radiotherapy and immunotherapy. Immunotherapy (2018) 10:851-800. doi: 10.2217/imt-2018-0019

122. Fang P, Jiang W, Allen P, Glitza I, Guha N, Hwu P, et al. Radiation necrosis with stereotactic radiosurgery combined with CTLA-4 blockade and PD-1 inhibition for treatment of intracranial disease in metastatic melanoma. $J$ Neurooncol. (2017) 133:595-602. doi: 10.1007/s11060-017-2470-4

123. Gettinger SN, Wurtz A, Goldberg SB, Rimm D, Schalper K, Kaech S, et al. Clinical features and management of acquired resistance to PD- 1 axis inhibitors in 26 Patients with advanced non-small cell lung cancer. J Thorac Oncol. (2018) 13:831-9. doi: 10.1016/j.jtho.2018.03.008

124. Hwang WL, Niemierko A, Hwang KL, Hubbeling H, Schapira E, Gainor JF, et al. Clinical Outcomes in Patients With Metastatic Lung Cancer Treated With PD-1/PD-L1 Inhibitors and Thoracic Radiotherapy. JAMA Oncol. (2018) 4:253-5. doi: 10.1001/jamaoncol.2017.3808

125. Verma V, Cushman TR, Selek U, Tang C, Welsh JW. Safety of combined immunotherapy and thoracic radiation therapy: analysis of 3 singleinstitutional phase I/II trials. Int J Radiat Oncol Biol Phys, (2018) 101:1141-8. doi: 10.1016/j.ijrobp.2018.04.054

126. Shaverdian N, Lisberg AE, Bornazyan K, Veruttipong D, Goldman JW, Formenti SC, et al. Previous radiotherapy and the clinical activity and toxicity of pembrolizumab in the treatment of non-small-cell lung cancer: a secondary analysis of the KEYNOTE-001 phase 1 trial. Lancet Oncol. (2017) 18:895-903. doi: 10.1016/S1470-2045(17)30380-7

127. Samstein R, Rimner A, Barker CA, Yamada Y. Combined immune checkpoint blockade and radiation therapy: timing and dose fractionation associated with greatest survival duration among over 750 treated patients. Int J Radiat Oncol Biol Phys. (2017) 99:S129-30. doi: 10.1016/j.ijrobp.2017.06.303 
128. Young KH, Baird JR, Savage T, Cottam B, Friedman D, Bambina S, et al. Optimizing timing of immunotherapy improves control of tumors by hypofractionated radiation therapy. PLOS ONE (2016) 11:e0157164. doi: 10.1371/journal.pone.0157164

129. Larkin J, Hodi FS, Wolchok JD. Combined Nivolumab and Ipilimumab or Monotherapy in Untreated Melanoma. N Engl J Med. (2015) 373:1270-1. doi: 10.1056/NEJMc1509660

130. Gandhi L, Rodriguez-Abreu D, Gadgeel S, Esteban E, Felip E, De Angelis F, et al. Pembrolizumab plus chemotherapy in metastatic non-small-cell lung cancer. N Engl J Med. (2018) 378:2078-92. doi: 10.1056/NEJMoa18 01005

131. Sharma P, Allison JP. Immune checkpoint targeting in cancer therapy: toward combination strategies with curative potential. Cell (2015) 161:20514. doi: 10.1016/j.cell.2015.03.030

132. Hughes PE, Caenepeel S, Wu LC. Targeted therapy and checkpoint immunotherapy combinations for the treatment of cancer. Trends Immunol. (2016) 37:462-76. doi: 10.1016/j.it.2016. 04.010

133. Verma V, Chang JY. Stereotactic ablative radiotherapy for oligometastatic non-small cell lung cancer. J Thorac Dis. (2018) 10:21-4. doi: $10.21037 /$ jtd.2017.11.141

134. Lustberg T, van Soest J, Gooding M, Peressutti D, Aljabar P, van der Stoep J, et al. Clinical evaluation of atlas and deep learning based automatic contouring for lung cancer. Radiother Oncol. (2018) 126:312-7. doi: 10.1016/j.radonc.2017.11.012

Conflict of Interest Statement: JW and JC have received research grants from Bristol-Myers Squibb. JW has also received grants from Varian Medical Systems and OncoResponse, and he is a co-founder of Healios, MolecularMatch, and OncoResponse. In addition, JW is on the scientific advisory boards for RefleXion Medical and Checkmate Pharmaceuticals and receives laboratory research support from Varian Medical Systems, Incyte, Calithera, and Checkmate Pharmaceuticals. JC is a shareholder of Global Oncology One.

The remaining authors declare that the research was conducted in the absence of any commercial or financial relationships that could be construed as a potential conflict of interest.

Copyright (C) 2019 Menon, Ramapriyan, Cushman, Verma, Kim, Schoenhals, Atalar, Selek, Chun, Chang, Barsoumian, Nguyen, Altan, Cortez, Hahn and Welsh. This is an open-access article distributed under the terms of the Creative Commons Attribution License (CC BY). The use, distribution or reproduction in other forums is permitted, provided the original author(s) and the copyright owner(s) are credited and that the original publication in this journal is cited, in accordance with accepted academic practice. No use, distribution or reproduction is permitted which does not comply with these terms. 